\author{
Davy C.H. Cheng MSc MD FRCPC, * \\ Frances Chung MD FRCPC, * \\ Kenneth R. Chapman MSc MD FRCPC FACP, $\dagger$ \\ Jack Romanelli BSc ${ }^{\dagger}$
}

\section{Low-dose sufentanil and lidocaine supple- mentation of general anaesthesia}

This randomized double-blind study compared the effects of: (I) saline infusion (C); (2) sufentanil alone $\left(1.0 \mu \mathrm{g} \cdot \mathrm{kg}^{-1}\right)(S)$; and (3) low-dose sufentanil $\left(0.5 \mu \mathrm{g} \cdot \mathrm{kg}^{-1}\right)$ in combination with lidocaine $\left(1.5 \mathrm{mg} \cdot \mathrm{kg}^{-1}\right)(L S)$; on the cardiovascular responses to tracheal intubation and on postoperative ventilation as monitored by respiratory inductive plethysmography in day-care surgical procedures of approximately $60 \mathrm{~min}$ duration. Thirty healthy, unpremedicated patients were studied. Thiopentone requirements were reduced by 40 and 28 per cent in the $S$ and $L S$ groups respectively compared with control $(P<0.001)$. Both treatments suppressed $H R$ and $B P$ responses $(P<0.005)$ to intubation. Postoperatively, $\mathrm{PaCO}_{2}$ was elevated $(P<0.05)$ in group $S$. Dose-related respiratory depression was observed. The incidence of postoperative apnoea was significantly higher in both $S$ and $L S$ groups than compared with control $(P<0.05)$. However, only patients in group $S$ showed higher apnoea index and mean apnoea duration over the initial $10-20 \mathrm{~min}$ after surgery compared with control $(P<0.005)$. In addition, group $S$ showed slower respiratory frequency and prolonged expiratory time $(P<0.005)$. In conclusion, an induction dose of sufentanil ( $\left(\mu \mathrm{g} \cdot \mathrm{kg}^{-1}\right.$ ) used in balanced anaesthesia of less than 70 min duration was associated with significant respiratory depression, particularly during the initial 10-20 min after

\section{Key words}

ANAESTHESIA: general, outpatient;

ANALGESICS: sufentanil;

MONITORING: ventilation, respiratory inductive plethysmography, vascular.

From the Departments of Anaesthesia* and Medicinet, University of Toronto, The Toronto Hospital, Toronto Western Division, Toronto, Ontario, Canada.

Address correspondence to: Dr. D. C.H. Cheng, Department of Anacsthesia, University of Toronto, The Toronto Hospital, Toronto Western Division, 399 Bathurst Street, Toronto, Ontario, Canada M5T $2 S 8$.

This study was presented in part at the 45th Annual Meeting of the Canadian Anacsthetists' Society in Halifax, N.S., June, 1988. Supported in part by a grant from Janssen Pharmaceutica, Inc., Canada. surgery, whereas low-dose sufentanil $\left(0.5 \mu \mathrm{g} \cdot \mathrm{kg}^{-1}\right)$ with lidocaine ( $1.5 \mathrm{mg} \cdot \mathrm{kg}^{-1}$ ) had minimal postoperative respiratory depression and comparable attenuation of pressor responses to intubation.

Cette étude randomisée à double-insu a comparé les effets de:(1) la perfusion de salin (C); (2) le sufentanil seul $\left(1,0 \mu \mathrm{g} \cdot \mathrm{kg}^{-1}\right)$ (S); et (3) une petite dose de sufentanil $\left(0,5 \mu \mathrm{g} \cdot \mathrm{kg}^{-1}\right)$ en combinaison avec la lidocaïne $\left(1,5 \mathrm{mg} \cdot \mathrm{kg}^{-1}\right)(L S)$; sur les réponses cardiovasculaires à l'intubation trachéale et la ventilation postopératoire telle qu'étudiée par plérhysmographie inductive pour une durée de 60 minutes. Trente patients en bonne santé, non prémédiqués ont été étudiés. Les doses de thiopentone ont été diminuées de 40 et 28 pour cent respectivement dans les groupes $S$ et $L S$ comparativement au contrôle $(P<0,001)$. Les deux régimes ont diminué la réponse de l'intubation sur la fréquence cardiaque et la tension artériclle $(P<0,005)$. En période postopératoire la $\mathrm{PaCO}_{2}$ était élevée $(P<0,05)$ dans le groupe $S$. Une dépression respiratoire dépendant de la dose a été observée. L'incidence d'apnée postopératoire a été significativement plus élevée dans le groupe $S$ et $L S$ comparativement au contrôle $(P<0,05)$. Cependant seulement les patients du groupe $S$ ont démontré un indice d'apnée supérieur et une durée d'apnée moyenne après chirurgie comparativement au contrôle $(P<0,005)$. En plus le groupe $S$ a démontré une fréquence respiratoire plus basse et un temps d'expiration prolongé $(P<0,005)$. En conclusion, une dose d'induction de sufentanil (I $\mu \mathrm{g} \cdot \mathrm{kg}^{-1}$ ) utilisée pour une anesthésie balancée d' une durée inférieure à 70 minutes est associée d̀ une dépression respiratoire significative, particulièrement durant le temps initial de 10 à 20 minutes après la chirurgie. Une dose moindre $\left(0,5 \mu \mathrm{g} \cdot \mathrm{kg}^{-1}\right)$ de sufentanil et de lidocaïne $\left(1,5 \mathrm{mg} \cdot \mathrm{kg}^{-1}\right)$ a présenté une dépression respiratoire minime en période postopératoire et une atténuation comparable de la réponse à l'intubation.

Sufentanil,' an analogue of fentanyl, is five to ten times more potent, has a more rapid onset of action, ${ }^{2}$ is more effective in preventing intraoperative hypertension and tachycardia, ${ }^{2-4}$ and results in less cumulative respiratory depression $^{5,6}$ than the parent compound. However, numerous cases of respiratory depression or arrest have been 
reported with sufentanil. ${ }^{7-11}$ Nonetheless, no detailed analysis of postoperative respiratory depression by sufentanil has been undertaken. With growing popularity in ambulatory care, relatively longer duration of surgery is being performed in outpatient settings and in patients with stable, complex diseases. The balance between detrimental cardiovascular responses ${ }^{12-14}$ to intubation and postoperative respiratory depression in the use of sufentanil in these surgical procedures has not been examined. Having shown that the cardiovascular response can be blunted by intravenous lidocaine prior to tracheal intubation, ${ }^{15}$ we sought to test the hypothesis that low-dose sufentanil in combination with lidocaine provided as stable a cardiovascular response to tracheal intubation and less postoperative respiratory depression than the recommended dose of sufentanil alone in a double-blind study in patients undergoing outpatient surgery lasting about $60 \mathrm{~min}$.

\section{Methods}

Human Experimentation Committee approval and informed consent were obtained. Thirty patients from the Short Stay Unit, aged 18-60 yr, of ASA physical status I-II and with no pre-existing cardiac or respiratory disease, undergoing elective surgical procedures that required tracheal intubation were studied. Surgical procedures that involved the thorax or abdomen were excluded.

No preoperative sedation was given. Flow-volume spirometry (570 Wedge, Med. Science Electronics, Inc., St. Louis, MO) and respiratory inductive plethysmographic calibration (Respitrace ${ }^{\circledR}$, Ambulatory Monitoring, Inc., Ardsley, NY) were performed before surgery. Patients were randomly allocated into three groups: control (C); lidocaine $\left(1.5 \mathrm{mg} \cdot \mathrm{kg}^{-1}\right)$ with sufentanil $(0.5$ $\left.\mu \mathrm{g} \cdot \mathrm{kg}^{-1}\right)(\mathrm{LS})$ and sufentanil alone $\left(1.0 \mu \mathrm{g} \cdot \mathrm{kg}^{-1}\right)(\mathrm{S})$. All patients were given $0.5 \mathrm{~L}$ crystalloid during the pre-oxygenation period. Baseline data were collected after five minutes of pre-oxygenation (time, $-5 \mathrm{~min}$ ), then precurarization of d-tubocurarine $0.05 \mathrm{mg} \cdot \mathrm{kg}^{-1}$ was given. At time $-3 \mathrm{~min}$, either normal saline or lidocaine $1.5 \mathrm{mg} \cdot \mathrm{kg}^{-1}$ was injected, followed by normal saline or sufentanil $\left(0.5\right.$ or $\left.1.0 \mu \mathrm{g} \cdot \mathrm{kg}^{-1}\right)$. At time $-2 \mathrm{~min}$, thiopentone was titrated in $50 \mathrm{mg}$ increments until loss of consciousness, as defined by loss of response to verbal command and loss of the eyelid reflex, assessed every 15 sec by two investigators during the induction of anaesthesia. Muscle relaxation was induced with succinylcholine $1.5 \mathrm{mg} \cdot \mathrm{kg}^{-1}$. At Time 0 , tracheal intubation was accomplished by the investigator within $20 \mathrm{sec}$. Controlled ventilation with 70 per cent nitrous oxide and 30 per cent oxygen was initiated. For the next five minutes, the patient was not surgically stimulated to allow haemodynamic measurements. Dosage of thiopentone used for induction was compared among groups.
Heart rate (HR), systolic (SBP) and diastolic blood pressures (DBP) were recorded by an automatic blood pressure cuff (Datascope ${ }^{\circledR}$ ) at: Time -5 min (baseline), $-4 \mathrm{~min}$ (precurarization), $-3 \mathrm{~min}$ (study drug), $-2 \mathrm{~min}$ (thiopentone), $-1 \mathrm{~min}, 0$ (laryngoscopy and intubation) and post-intubation every minute for five minutes. Atropine $0.6 \mathrm{mg} \mathrm{IV}$ was administered to patients if the HR was less than $50 \mathrm{bpm}$ during continuous ECG monitoring.

Anaesthesia was maintained with 70 per cent nitrous oxide and 30 per cent oxygen, supplemented with vecuronium to maintain muscle relaxation as monitored with a nerve stimulator. Isoflurane was added to maintain the blood pressure within 20 per cent of the preoperative level. Ventilation was controlled to maintain the endtidal $\mathrm{PCO}_{2}$ at $35-40 \mathrm{mmHg}$. No additional doses of an opioid were given intraoperatively. At the end of the surgical procedure, neuromuscular blockade was reversed with neostigmine and glycopyrrolate and confirmed with train-of-four stimulation. The patients' tracheas were extubated in the operating room when they were awake, breathing spontaneously, and able to sustain head lift and strong hand grasp. The end-expiratory concentration of isoflurane was zero in all patients as monitored by mass spectrometry (Perkin Elmer) at the time of extubation. Extubation was accomplished within five minutes of the completion of surgery.

Details of the DC-coupled respitrace have been published ${ }^{16}$ and its accuracy has been confirmed in a variety of settings. ${ }^{17-19}$ Respiratory Inductive Plethysmograph (RIP) consists of two coils of teflon-insulated wire which are placed around the rib cage and abdomen to measure its cross-sectional area. This produces a proportional change in self-inductance of that coil which is related to lung volume. The RIP is not sensitive to changes in body position, and a single calibration with a spirometer by changing body position from the upright to the supine position is valid over a wide range of body positions. ${ }^{16,17}$ Calibration factors were calculated by the simultaneous equations method using the mean of two resting tidal breaths from the tidal volume record. Validation of correct calibration was obtained by measuring tidal volume (VT) simultaneously with RIP and spirometer during 20 seconds rebreathing from the spirometer. If the mean VT, calculated from RIP as the sum of rib-cage and abdominal contributions was greater than \pm 10 per cent from the mean VT measured spirometrically, the inductance coils were re-applied and the calibration procedure repeated until the difference was less than ten per cent or the patient was excluded from the study.

The ventilatory pattern was monitored by RIP for ten minutes preoperatively and postoperatively at $10-20 \mathrm{~min}$, 30-40 $\mathrm{min}$ and 50-60 min intervals after extubation. Analogue RIP signals were digitized at $20 \mathrm{~Hz}$ and data 
were collected on microcomputer diskette as well as on a multichannel strip chart recorder for subsequent analysis. Breath detection software allowed breath-by-breath measurement or calculation of the following variables: respiratory frequency $(\mathrm{F})$, inspiratory time $(\mathrm{TI})$, expiratory time (TE), tidal volume (VT), mean inspiratory flow rate (VT/TI), minute ventilation ( $\dot{\mathrm{VE}}$ ) and percentage of rib cage or abdominal contribution to VT. Apnoeas were defined as expiratory pauses of greater than ten seconds during which no tidal volume effort was discernible or the VT was less than $100 \mathrm{ml}$. The apnoea index was defined by the number of apnoeas per hour as expressed during the three ten-minute periods after extubation. All patients received 28 per cent oxygen by facemask and haemoglobin saturation was monitored by pulse oximetry. Naloxone $0.2 \mathrm{mg}$ IV was only given to patients with prolonged apnoea that was accompanied by arterial desaturation, i.e., less than 90 per cent. Arterial blood gas analyses were performed at $30 \mathrm{~min}$ after surgery. Postoperatively, morphine IV was given for pain as needed by the recovery room nurses after the respitrace was attached to the patients.

Data were expressed as mean \pm SEM. Statistical analysis was done by a one-way ANOVA and was followed by Scheffe's multiple range test during post-hoc analysis of significant overall F's from the one-way ANOVA. The effect of time and group difference were correlated with repeated measures analysis of variance. Due to multiple comparisons, Bonferonni's adjustment for the level of significance was applied.

\section{Results}

Thirty healthy patients from the Short Stay Unit were studied with ten in each group. There were no differences among the three groups in age, weight or duration of anaesthesia and surgery (Table I). The thiopentone dose requirement was significantly lower in the $\mathrm{LS}$ and $\mathrm{S}$ groups than in the control group. When active treatment groups were compared, thiopentone requirements were significantly lower in the $S$ than the LS group (Table II).

Heart rate (HR) in the control group was significantly increased above baseline at intubation and at two minutes following intubation. The mean HR in the LS and $S$ groups changed minimally from baseline and was signifi-

TABLE I Comparison of demographic data

\begin{tabular}{lccc}
\hline & $C$ & \multicolumn{1}{l}{$L S$} & \multicolumn{1}{l}{$S$} \\
$n$ & 10 & 10 & \multicolumn{1}{l}{10} \\
\hline Age (yr) & $33 \pm 4$ & $38 \pm 3$ & $27 \pm 2$ \\
Body weight (kg) & $73.3 \pm 5.0$ & $70.1 \pm 3.3$ & $70.6 \pm 3.5$ \\
Height (cm) & $168 \pm 2$ & $169 \pm 2$ & $170 \pm 3$ \\
Surgery (min) & $70.8 \pm 8.2$ & $74.8 \pm 8.2$ & $67.1 \pm 8.8$ \\
\hline
\end{tabular}

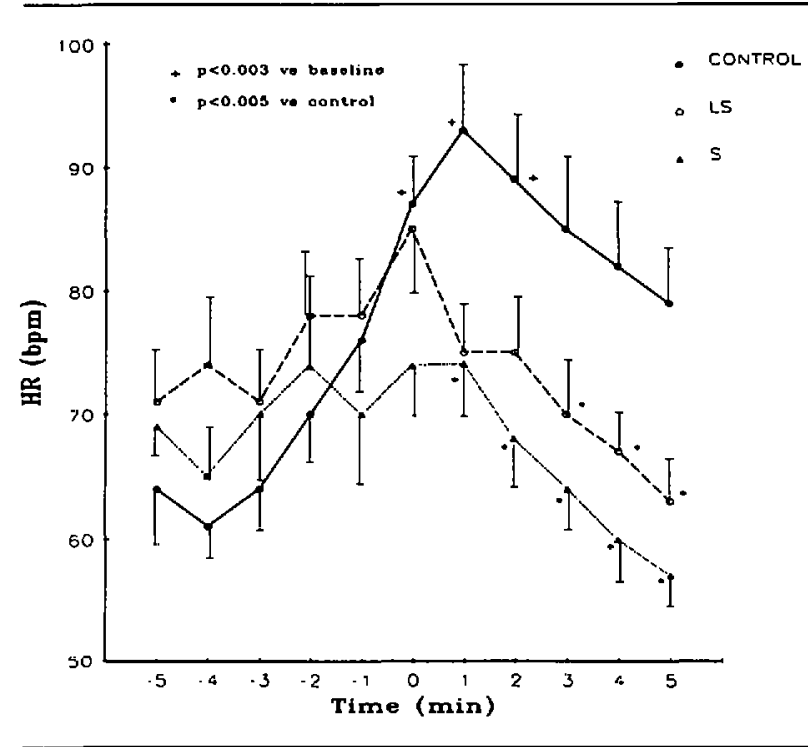

FIGURE I Comparison of heart rate among control $(C)$, lidocainesufentanil (LS) and sufentanil (S) groups over time. Baseline ( -5 $\mathrm{min})$, precurarization $(-4 \mathrm{~min})$, study drug ( $-3 \mathrm{~min})$, thiopental $(-2$ $\mathrm{min}$ ) and intubation $(0 \mathrm{~min})$ (mean $\pm \mathrm{SEM})$.

cantly lower than in the control group post-intubation (Figure 1). Systolic (SBP) and diastolic blood pressures (DBP) showed similar response profiles and were elevated markedly at one minute post-intubation in the control group. In contrast, SBP and DBP in the LS and S groups did not increase from baseline and were significantly lower than control group post-intubation (Figures 2 and 3 ). One patient in each LS and $S$ group required intravenous atropine $0.6 \mathrm{mg}$ post-intubation because of bradycardia (HR $<50 \mathrm{bpm}$ ).

Postoperatively, the arterial oxygen saturation was not significantly different among the three groups, ranging from 98-99 per cent. However, $\mathrm{PaCO}_{2}$ was significantly elevated in the $\mathrm{S}$ group (Table II). One patient in group $\mathrm{S}$ exhibited a $\mathrm{PaCO}_{2}$ of $69 \mathrm{mmHg}$ and $\mathrm{SaO}_{2}$ of 97 per cent at 30 min postoperation, with spontaneous improvement to 56 and $48 \mathrm{mmHg}$ at 60 and $90 \mathrm{~min}$ respectively. No

TABLE II Comparison of thiopentone requirement and postoperative arterial oxygen saturation and carbon dioxide tension

\begin{tabular}{llll}
\hline & $C$ & $L S$ & $S$ \\
$n$ & 10 & 10 & 10 \\
\hline Thiopentone $\left(\mathrm{mg} \cdot \mathrm{kg}^{-1}\right)$ & $5.0 \pm 0.2$ & $3.6 \pm 0.2^{*}$ & $3.0 \pm 0.2^{* \dagger}$ \\
$\mathrm{SaO}_{2}(\%)$ & $99 \pm 1$ & $99 \pm 1$ & $99 \pm 1$ \\
$\mathrm{PaCO}_{2}(\mathrm{mmHg})$ & $40.4 \pm 1.7$ & $45.5 \pm 2.0$ & $50.0 \pm 3.1 \ddagger$ \\
\hline
\end{tabular}

Mean \pm SEM

$* P<0.001$ vs $C$.

$\dagger P<0.05$ vs LS.

$\ddagger P<0.05$ vs $C$. 


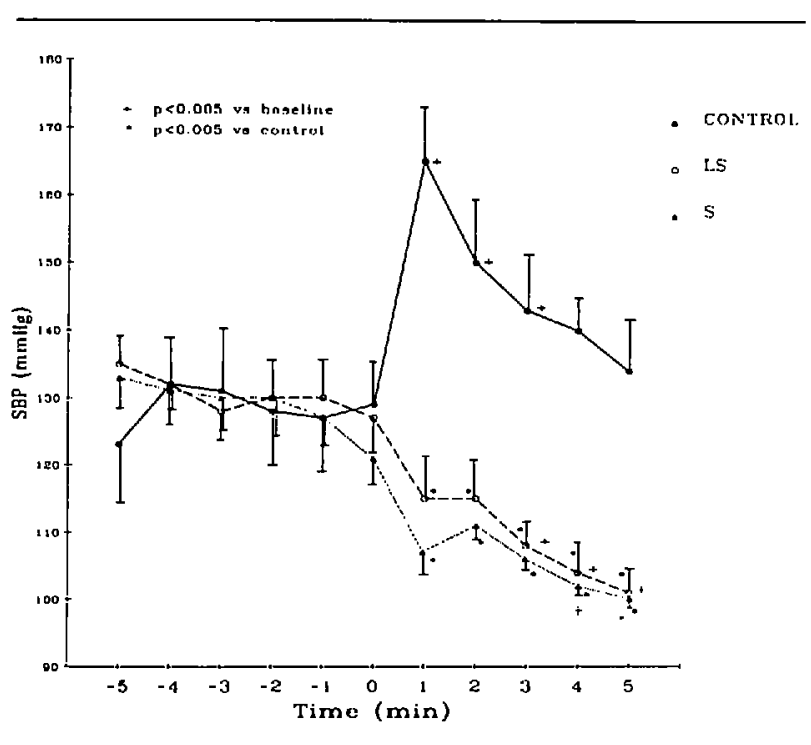

FIGURE 2 Comparison of systolic blood pressure among control (C), lidocaine-sufentanil (LS) and sufentanil (S) groups over time.

Baseline ( $-5 \mathrm{~min})$, precurarization $(-4 \mathrm{~min})$, study drug $(-3 \mathrm{~min})$, thiopentone $(-2 \mathrm{~min})$ and intubation $(0 \mathrm{~min})(\mathrm{mean} \pm \mathrm{SEM})$.

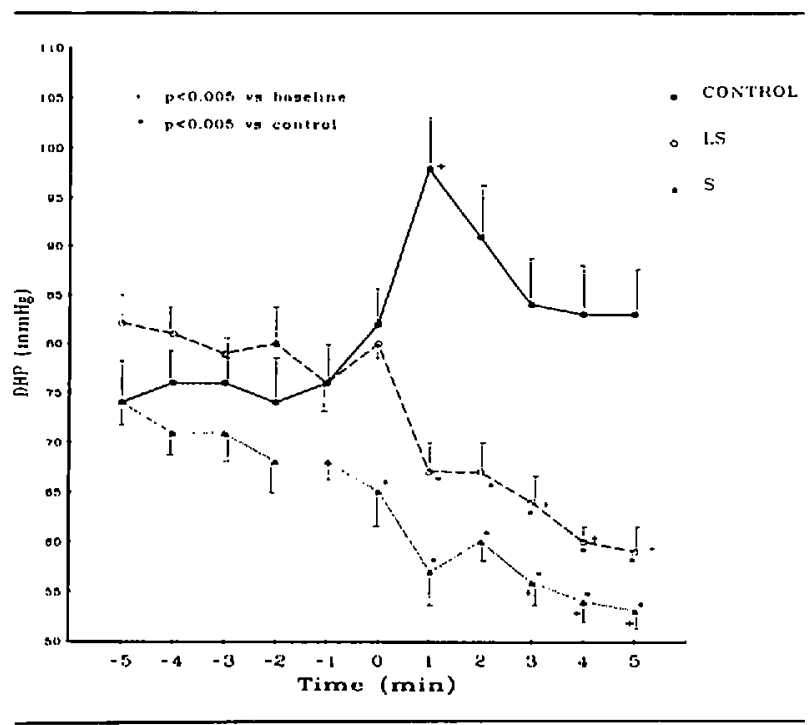

FIGURE 3 Comparison of diastolic blood pressurc among control (C), lidocaine-sufentanil (LS) and sufentanil (S) groups over time. Baseline ( $-5 \mathrm{~min})$, precurarization $(-4 \mathrm{~min})$, study drug $(-3 \mathrm{~min})$, thiopentonc $(-2 \mathrm{~min})$ and intubation $(0 \mathrm{~min})$ (mean \pm SEM).

postoperative analgesia was required by this patient. Postoperative ventilatory patterns were significantly different among the treatment groups. The number of patients exhibiting apnoeas was also higher $(P<0.05)$ in LS and $S$ groups (6/10 and $8 / 10$ patients, respectively) versus control ( $1 / 8$ patients). The highest apnoea index (number of apneas $\cdot \mathrm{hr}^{-1}$ ) was seen in the $\mathrm{S}$ group at $10-20$ min postoperation; this value was significantly higher

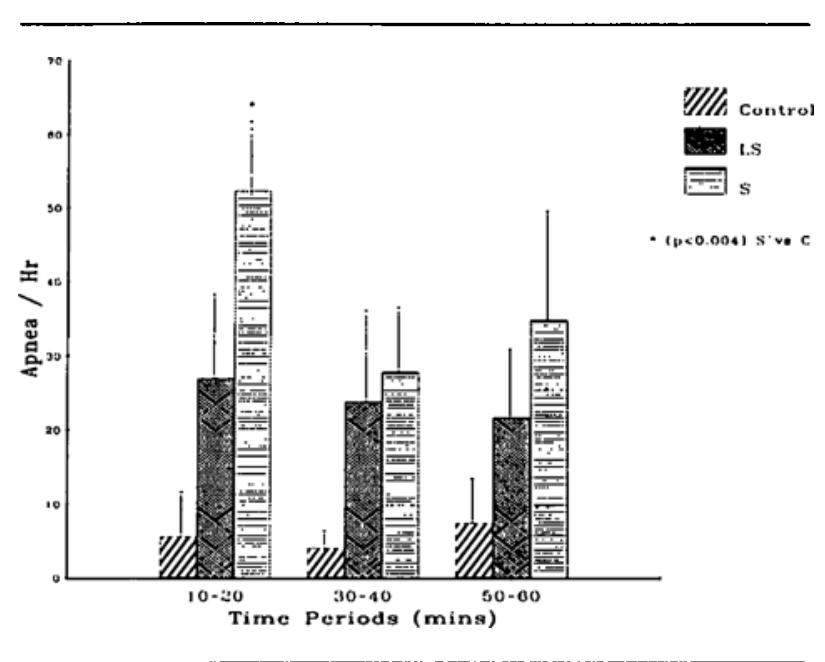

FIGURE 4 Apnoed index (mean \pm SEM) among the three groups at different time intervals after operation.

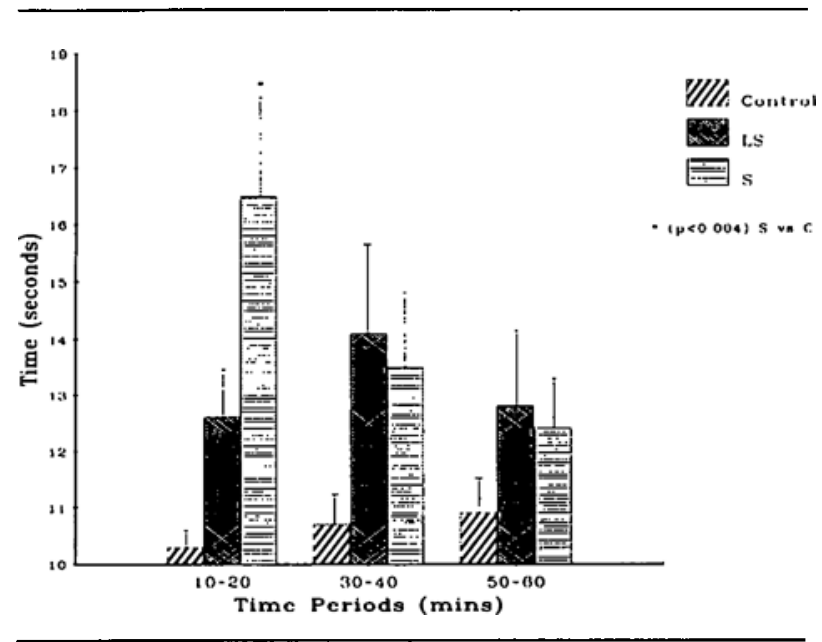

FIGURE 5 Apnoca duration (mean \pm SEM) among patients with apnoea in the three groups at different time intervals after operation.

than in control and LS groups (Figure 4). Among patients with apnoeas, the mean apnoea duration showed a dose-response relationship to sufentanil particularly during the earliest postoperative monitoring period $(P<$ 0.005 ) (Figure 5). Ventilatory pattern variables are summarized in Table III for pre-and postoperative monitoring periods. For technical reasons, data were incomplete for two control subjects and data are shown for eight control subjects. At ten minutes postoperatively, respiratory frequency (F) was significantly lower and expiratory time (TE) significantly longer in the $S$ group compared with baseline and compared with the control and LS groups.

More patients tended to require postoperative analgesia in the control ( 40 per cent) than in the LS ( 20 per cent) and 
TABLE III Detailed comparisons of ventilation variables by respiratory inductive plethysmography

\begin{tabular}{|c|c|c|c|}
\hline & $C(n=8)$ & $L S(n=10)$ & $S(n=10)$ \\
\hline \multicolumn{4}{|c|}{ Frequency (F) (breaths per minute) } \\
\hline Baseline & $15 \pm 1$ & $16 \pm 1$ & $15 \pm 1$ \\
\hline Postop $10-20 \mathrm{~min}$ & $16 \pm 1$ & $13 \pm 1$ & $10 \pm 1^{*}$ \\
\hline Postop 30-40 min & $15 \pm 1$ & $13 \pm 1$ & $13 \pm 1$ \\
\hline Postop 50-60 min & $15 \pm 1$ & $13 \pm 1$ & $14 \pm 1$ \\
\hline \multicolumn{4}{|c|}{ Inspiratory time (TI) sec } \\
\hline Baseline & $1.7 \pm 0.2$ & $1.6 \pm 0.2$ & $1.9 \pm 0.2$ \\
\hline Postop $10-20 \mathrm{~min}$ & $1.6 \pm 0.1$ & $1.8 \pm 0.1$ & $1.8 \pm 0.1$ \\
\hline Postop $30-40 \mathrm{~min}$ & $1.7 \pm 0.1$ & $1.7 \pm 0.1$ & $1.7 \pm 0.1$ \\
\hline Postop 50-60 min & $1.6 \pm 0.1$ & $1.7 \pm 0.1$ & $1.6 \pm 0.1$ \\
\hline \multicolumn{4}{|c|}{ Expiratory time (TE) sec } \\
\hline Bascline & $2.5 \pm 0.3$ & $2.4 \pm 0.3$ & $2.6 \pm 0.3$ \\
\hline Postop 10-20 min & $2.7 \pm 0.8$ & $4.1 \pm 0.8$ & $6.6 \pm 0.8 \dagger$ \\
\hline Postop 30-40 min & $2.8 \pm 0.6$ & $4.2 \pm 0.5$ & $4.2 \pm 0.6$ \\
\hline Postop 50-60 min & $2.8 \pm 0.5$ & $4.0 \pm 0.4$ & $4.1 \pm 0.5$ \\
\hline \multicolumn{4}{|l|}{ Tidal volume (VT) L } \\
\hline Bascline & $0.50 \pm 0.07$ & $0.48 \pm 0.07$ & $0.61 \pm 0.06$ \\
\hline Postop 10-20 min & $0.57 \pm 0.07$ & $0.56 \pm 0.06$ & $0.67 \pm 0.06$ \\
\hline Postop 30-40 min & $0.58 \pm 0.06$ & $0.56 \pm 0.05$ & $0.63 \pm 0.06$ \\
\hline Postop 50-60 min & $0.48 \pm 0.06$ & $0.53 \pm 0.05$ & $0.58 \pm 0.05$ \\
\hline \multicolumn{4}{|c|}{ Minute ventilation per wt $\left(\dot{\mathrm{VE} \mathrm{kg}} \mathrm{kg}^{-1}\right)\left(\mathrm{ml} \cdot \mathrm{min}^{-1} \cdot \mathrm{kg}^{-1}\right)$} \\
\hline Baseline & $0.09 \pm 0.01$ & $0.11 \pm 0.01$ & $0.12 \pm 0.01$ \\
\hline Postop 10-20 min & $0.11 \pm 0.02$ & $0.10 \pm 0.02$ & $0.10 \pm 0.02$ \\
\hline Postop 30-40 min & $0.11 \pm 0.02$ & $0.10 \pm 0.02$ & $0.12 \pm 0.02$ \\
\hline Postop 50-60 min & $0.09 \pm 0.02$ & $0.10 \pm 0.01$ & $0.11 \pm 0.02$ \\
\hline \multicolumn{4}{|c|}{ Respiratory drive (VT/TI) (litrc $\left.\cdot \mathrm{sec}^{-1}\right)$} \\
\hline Baseline & $0.29 \pm 0.03$ & $0.30 \pm 0.03$ & $0.33 \pm 0.03$ \\
\hline Postop $10-10 \mathrm{~min}$ & $0.37 \pm 0.06$ & $0.32 \pm 0.05$ & $0.39 \pm 0.05$ \\
\hline Postop $30-40 \mathrm{~min}$ & $0.36 \pm 0.05$ & $0.34 \pm 0.04$ & $0.41 \pm 0.04$ \\
\hline Postop 50-60 min & $0.31 \pm 0.03$ & $0.32 \pm 0.02$ & $0.37 \pm 0.03$ \\
\hline \multicolumn{4}{|l|}{ \% Rib ventilation } \\
\hline Baseline & $38.6 \pm 8.6$ & $47.9 \pm 8.6$ & $51.4 \pm 8.1$ \\
\hline Postop $10-20 \mathrm{~min}$ & $56.3 \pm 6.2$ & $63.4 \pm 5.6$ & $56.8 \pm 5.6$ \\
\hline Postop 30-40 min & $52.8 \pm 6.6$ & $62.4 \pm 5.9$ & $55.7 \pm 6.3$ \\
\hline Postop 50-60 min & $47.0 \pm 6.5$ & $58.4 \pm 5.5$ & $56.9 \pm 6.1$ \\
\hline \multicolumn{4}{|c|}{$\%$ Abdomen ventilation } \\
\hline Baseline & $61.4 \pm 8.6$ & $52.1 \pm 8.6$ & $48.6 \pm 8.1$ \\
\hline Postop 10-20 min & $43.7 \pm 6.2$ & $36.6 \pm 5.6$ & $43.2 \pm 5.6$ \\
\hline Postop 30-40 min & $47.2 \pm 6.6$ & $37.6 \pm 5.9$ & $44.3 \pm 6.3$ \\
\hline Postop 50-60 min & $53.0 \pm 6.5$ & $41.6 \pm 5.5$ & $43.2 \pm 6.1$ \\
\hline
\end{tabular}

Mean \pm SEM

$* P<0.05$ vs LS

$P<0.005$ vs C.

$P<0.005$ vs baseline.

$$
\begin{aligned}
+P & <0.05 \text { vs } L S . \\
P & <0.005 \text { vs } C . \\
P & <0.05 \text { vs baseline. }
\end{aligned}
$$

$S$ (ten per cent) groups during an hour stay in the recovery room. The morphine dosage ranged from 2-4 mg IV and was not correlated to the occurrence of apnoea among the patients.

\section{Discussion}

Our data show that sufentanil reduced the thiopentone requirement for induction of anaesthesia in the $\mathrm{LS}$ or $\mathrm{S}$ groups by 28 and 40 per cent respectively in unpremedicated young healthy individuals (Table I). The most marked responses in heart rate (HR), systolic (SBP) and diastolic blood pressures (DBP) were manifested at one minute after tracheal intubation in the control group. The supplementation of lidocaine, which has been shown to suppress the cough reflex ${ }^{20}$ and to blunt hypertension and tachycardia during tracheal intubation, ${ }^{21}$ with low-dose sufentanil was as effective as sufentanil alone in a conventional dose in blunting the cardiovascular responses to intubation (Figures 1-3) in our study. One patient in each of the LS and $S$ groups exhibited bradycardia following tracheal intubation when anaesthesia was maintained with 33 per cent $\mathrm{O}_{2}-\mathrm{N}_{2} \mathrm{O}$ without surgical stimulation. Blood pressures were stable and the hear rates increased promptly following atropine IV $0.6 \mathrm{mg}$. No hypotension or rigidity was observed in any subject.

The major objective of this study was to compare the two treatment groups with respect to postoperative respiratory depression in outpatient surgical procedures. Although cases of respiratory depression after sufentanil have been reported, ${ }^{7-11}$ this depressive effect has only been estimated grossly by a decrease in respiratory rate or by cyanosis in patients after operation. It is the clinical impression that patients need to be stimulated constantly in the recovery room after sufentanil anaesthesia. In the present study, the respiratory induction plethysmography (RIP) ${ }^{16-19}$ was used to measure postoperative respiratory functions in the recovery room. This allowed continuous monitoring of ventilation with minimal disturbance to patients, making it ideal for assessing postoperative respiratory function in the "natural" recovery room setting. However, it did not measure the patient's ability to respond to hypercarbia or hypoxaemia.

The effect of isoflurane on postoperative respiratory function was minimal in our study groups. The isoflurane vaporizer was turned off at least five to eight minutes before the termination of surgery. As well, the maximum isoflurane inspiratory concentration was never higher than 0.5 per cent in the sufentanil groups, being typically about 0.25 per cent for the LS group and minimally on and off for the $\mathbf{S}$ group. Although halothane and enflurane have been shown to reduce the hypoxic reflex proportionally more than ventilation and the carbon dioxide response, even at 0.1 MAC sedation dose in humans, ${ }^{22}$ all our patients had zero end-tidal isoflurane concentration prior to tracheal extubation in the operating room. Also, arterial oxygen saturation was 99 per cent in all patients during the recovery period.

The circulatory changes seen during tracheal intubation 
have been ascribed to reflex stimulation of the autonomic nervous system. ${ }^{23}$ Many methods have been used to attenuate the adverse response to laryngoscopy and intubation including increasing the depth of inhalational anaesthesia, ${ }^{24}$ narcotic analgesics, ${ }^{3-5}$ lidocaine, ${ }^{15}$ vasodilators ${ }^{25}$ and beta blockers. ${ }^{26}$ Lidocaine IV has been found to suppress the cough reflex, ${ }^{20}$ to prevent increases in intracranial pressure, ${ }^{29}$ to attenuate circulatory responses $^{21}$ and to possess anti-arrhythmic properties. ${ }^{28}$ In the present study, we utilized these effects of lidocaine in supplementing low-dose sufentanil to achieve a balance in haemodynamic control and postoperative respiratory depression than just from the conventional dose of sufentanil.

The dose of lidocaine used in the LS group at induction of anaesthesia would have had no effect on postoperative respiratory function after $70 \mathrm{~min}$ of surgery. Pharmacokinetically, the plasma concentration of lidocaine is very low $70 \mathrm{~min}$ after IV injection. A blood level of $3 \mu \mathrm{g} \cdot \mathrm{kg}^{-1}$ is reached between $2-5 \mathrm{~min}$ after IV lidocaine administration. ${ }^{29}$ About 70 per cent lidocaine is bound to plasma proteins, distribution is rapid and its apparent volume of distribution is about $1 \mathrm{~L} \cdot \mathrm{kg}^{-1} .{ }^{30}$ Pharmacodynamically, subtle neurological symptoms may occur only at plasma concentrations near $5 \mu \mathrm{g} \cdot \mathrm{kg}^{-1}$. Therefore, we believe that the postoperative respiratory function measured by the RIP reflect the effects of sufentanil used in the study groups.

Low doses of sufentanil have been reported to produce both longer ${ }^{31}$ and shorter ${ }^{32}$ durations of respiratory depression than equivalent doses of fentanyl, but rigorous, quantitative measurements of respiratory drive were not employed in those studies. Brizgys et al ${ }^{33}$ compared sufentanil 0.5 and $1.0 \mu \mathrm{g} \cdot \mathrm{kg}^{-1}$ as an adjunct to thiopentone induction of anaesthesia. They found all patients' tracheas could be extubated at the end of the operation without the need for narcotic antagonists. However, their surgical duration ranged from $25 \mathrm{~min}$ to $8.5 \mathrm{hr}$. In the present study, although postoperative arterial oxygen saturation was well maintained at 99 per cent with supplemented oxygen, $\mathrm{PaCO}_{2}$ was significantly elevated in the $\mathbf{S}$ group 30 minutes postoperation (Table II). Postoperative ventilatory patterns were significantly different among the three groups. The control group showed the most regular respiratory pattern; recurrent apnoea and compensatory hyperventilation were common in both active treatment groups but were most marked in the $S$ group. Our data showed that the initial 10-20 min after operation was the most vulnerable period for patients to develop postoperative respiratory depression. The mean apnoea index was higher $(P<0.005)$ in the $S$ group especially in the initial $10-20$ min period after operation (Figure 4). The mean apnoea index tended to decrease over an hour of observation whereas no decrease was observed in $\mathrm{S}$ group. The mean apnoea duration, among those patients with apnoea, showed a dose relationship of $10.3,12.6$ and $16.5 \mathrm{sec}$ in groups $\mathrm{C}$, LS and $\mathrm{S}$ respectively, in the initial $10-20 \mathrm{~min}$ after operation (Figure 5). This suggests the importance of close observation in these patients in the initial 10-20 min after surgery. No difference was found between the LS and control groups in both apnoea index and apnoea duration. Although there is a 0.3 chance of a type-II error for the LS group to be different from control in the apnoea index measurement (Figure 4), the likelihood of a type-II error in the apnoea duration is 0.002 between the two groups (Figure 5) over the initial $10-20 \mathrm{~min}$ period after operation.

Detailed postoperative pulmonary function (Table III) also indicated that the most vulnerable period was at the initial 10-20 min and that patients in the $S$ group showed significantly decreased respiratory rates and prolonged expiratory times. However, RIP does not measure the hypercarbic or hypoxaemic responses in patients. Greater analgesia in the recovery period for the $\mathrm{S}$ and LS groups was also suggested in the number of patients requiring supplemental postoperative analgesia.

In summary, our findings indicate that, when the conventional induction dose of sufentanil $\left(1 \mu \mathrm{g} \cdot \mathrm{kg}^{-1}\right)$ is used in balanced anaesthesia for surgical procedures less than $70 \mathrm{~min}$, considerable risk of postoperative respiratory depression overrides its advantages in attenuating the pressor responses to intubation. The use of low-dose sufentanil $\left(0.5 \mu \mathrm{g} \cdot \mathrm{kg}^{-1}\right)$ with lidocaine $\left(1.5 \mathrm{mg} \cdot \mathrm{kg}^{-1}\right)$ achieves comparable attenuation of pressor responses to intubation and with minimal respiratory depression.

\section{Acknowledgments}

The authors would like to thank Miss Christine Drane for her excellent secretarial assistance and the ENT and General Surgery surgeons for their cooperation in this study.

\section{References}

1 Rosow CE. Sufentanil nitrate: a new opioid analgesic for use in anesthesia. Pharmacotherapy 1984; 4: 11-9.

2 de-Lange S, Boscoe MJ, Stanley TH, Pace N. Comparison of sufentanil- $\mathrm{O}_{2}$ and fentanyl- $\mathrm{O}_{2}$ for coronary artery surgery. Anesthesiology 1982; 56: 112-8.

3 Gnonneim MM, Dhanavaj J, Choi WW. Comparison of four opioid analgesics as supplements to nitrous oxide anesthesia. Anesth Analg 1984; 63: 405-12.

4 Flacke JW, Kripke BK, Bloor BC, Flacke WE, Katz $R L$. Intraoperative effectiveness of sufentanil, fentanyl, meperidine or morphine in balanced anesthesia: a doubleblind study. Anesth Analg 1983; 62: 259-60. 
5 Kay B, Rolly $G$. Duration of action of analgesic supplements to anesthesia: a double-blind comparison between morphine, fentanyl and sufentanil. Acta Anaesthesiol Belg 1977; 28: 25-32.

6 Clark NJ, Meuleman T, Liu WS, Zwanikken P, Pace NL, Stanley $\mathrm{TH}$. Comparison of sufentanil- $\mathrm{N}_{2} \mathrm{O}$ and fentanyl- $\mathrm{N}_{2} \mathrm{O}$ in patients without cardiac disease undergoing general surgery. Anesthesiology 1987; 66: 130-5.

7 Murkin JM. Sufentanil anaesthesia for major surgery: the multicentre Canadian clinical trial. Can J Anaesth 1989; 36: 343-9.

8 Wiggum DC, Cork RC, Weldon ST, Gandolfi AJ, Perry $D S$. Postoperative respiratory depression and elevated sufentanil levels in a patient with chronic renal failure. Anesthesiology 1985; 63: 708-10.

9 Chang J, Fish KJ. Acute respiratory arrest and rigidity after anesthesia with sufentanil: a case report. Anesthesiology 1985; 63: 710-1.

10 Goldberg M, Ishak S, Garcia C, McKenna J. Postoperative rigidity following sufentanil administration. Anesthesiology 1985; 63: 199-201.

11 Robinson $D$. Respiratory arrest after recovery from anaesthesia supplemented with sufentanil. Can J Anaesth 1988; 35: 101-2.

12 Prys-Roberts $C$, Greene $L T$, Meloche R, Föex $P$. Studies of anaesthesia in relation to hypertension II: haemodynamic consequences of induction and endotracheal intubation. Br J Anaesth 1971; 43: 531-46.

13 Fox EJ, Sklar GS, Hill CH, Villanueva R, King BD. Complications related to the pressor response to endotracheal intubation. Anesthesiology 1977; 47: 524-5.

14 Roy WL, Edelist $G$, Gilbert $B$. Myocardial ischemia during non-cardiac surgical procedurcs in patients with coronary artery discasc. Anesthesiology 1979; 51: 393-7.

15 Tam $S$, Chung $F$, Campbell $M$. Attenuation of circulatory responses to endotracheal intubation using IV lidocaine: a determination of the optimal time of injection. Anesth Analg 1987; 66: 1036-8.

16 Chadha TS, Watson H, Birch S et al. Validation of respiratory inductive plethysmography using different calibration procedures. Am Rev Respir Dis 1982; 125: 644-9.

17 Chapman KR, Rebuck AS. Thoracoabdominal motion during progressive isocapnic hypoxia in conscious man. J Physiol (London) 1984; 349: 73-82.

18 Chapman KR, Rebuck AS. Effect of posture on thoracoabdominal movements during $\mathrm{CO}_{2}$ rebreathing. J Appl Physiol 1984; 56: 97-101.

19 Chapman KR, Perl A, Zamel N, Rebuck AS. Thoracoabdominal motion during hypercapnia, hypoxia and exercise. Can J Physiol Pharmacol 1985; 63: 188-92.
20 Poulton TJ, James $F M$. Cough suppression by lidocaine. Anesthesiology 1979; 50: 470-2.

21 Abou-Madi MN, Keszler H, Yacoub JM. Cardiovascular reactions to laryngoscopy and tracheal intubation following small and large doses of lidocaine. Can Anaesth Soc J 1977; 24: 12-9.

22 Knill RL, Clement JL. Variable effects of anaesthetics on the ventilatory responsc to hypoxaemia in man. Can Anaesth Soc J 1982; 29: 93-9.

23 Tomori Z, Widdicombe JG. Muscular, bronchomotor and cardiovascular reflexes elicited by mechanical stimulation of the respiratory tract. J Physiol (Lond) 1969; 200: 25-49.

24 Delaney TJ, Kistner JR, Lake CL, Miller ED Jr. Myocardial function during halothane and enflurane in patients with coronary artery disease. Ancsth Analg 1980; 59: 240-4.

25 Stoelting $R K$. Attenuation of blood pressure response to laryngoscopy and tracheal intubation with sodium nitroprusside. Anesth Analg 1979; 58: 116-9.

26 Liu PL, Gatt S, Gugino LD, Mallampati SR, Covino $B G$. Esmolol for control of increases in heart rate and blood pressure during tracheal intubation after thiopentone and succinylcholine. Can Anaesth Soc J 1986; 33: 556-62.

27 Donegan $M F$, Bedford $R F$. Intravenously administered lidocaine prevents intracranial hypertension during endotracheal suctioning. Anesthesiology 1980; 52: 516-8.

28 Collinsworth KA, Kalman SM, Harrison DC. The clinical pharmacology of lidocaine as an anti-arrhythmic drug. Circulation 1974; 50: 1217-30.

29 Veigas $O$, Stoelting $R K$. Lidocaine in arterial blood after laryngotracheal administration. Anesthesiology 1975; 43: 491-3.

30 Boyes RN, Scott DB, Jebson PJ, Godman MJ, Julian $D G$. Pharmacokinetics of lidocaine in man. Clin Pharmacol Ther $1971 ; 12$ : 105-16.

31 Van de Walle J, Lauwers $P$, Adriaensen $H$. Double blind comparison of fentanyl and sufentanil in anesthesia. Acta Anaesthesiol Belg 1976; 27: 129.

32 Kalenda $Z$, Sheiigrond $H W$. Anaesthesia with sufentanilanalgesia in carotid and vertebral arteriography: a comparison with fentanyl. Anacsthetist 1976; 25: 380.

33 Brizgys RV, Morale SR, Owens B. Low-dose sufentanil: effects on thiopental requirements and hemodynamic responses during induction and intubation. Anesthesiology 1985; 63: A377. 